\title{
The Ten-Year Follow-Up of the Bedford Survey (1962-1972): Glucose Tolerance and Diabetes
}

\author{
H. Keen ${ }^{1}$, R. J.Jarrett ${ }^{2}$ and P. McCartney ${ }^{1}$ \\ Unit for Metabolic Medicine and 2Department of Community Medicine, Guy's Hospital Medical School, London, UK
}

Summary. In a 10-year prospective study of 241 people with 'borderline diabetes' (impaired glucose tolerance) identified by screening of the Bedford adult population, $36(15 \%)$ worsened to diabetes and 128 $(53 \%)$ substantially improved their glucose tolerance. The major predictor of worsening to diabetes was the level of blood glucose at baseline. This was statistically significant $(p<0.05)$, independent of other factors, both for deterioration in the first and in the second five years of observation. Body mass index, a measure of adiposity, did not predict worsening to diabetes during the first five years, but was an independent and significant predictor of worsening during the second five years $(p<0.05)$. The apparent effect of adiposity was complex, for it was also significantly related to improvement in glucose tolerance during the 10-year follow-up. Persons with impaired glucose tolerance are a heterogeneous group and with present knowledge the ability to predict metabolic deterioration is limited.

Key words: Diabetes mellitus, impaired glucose tolerance, obesity, prospective study.

In 1962 a diabetes survey was carried out in Bedford [1]. Subjects with post-prandial glycosuria plus a stratified random sample of the co-operating population were given an oral glucose load of $50 \mathrm{~g}$ glucose $(235 \mathrm{ml}$ liquid glucose) and a capillary blood glucose sample taken $2 \mathrm{~h}$ later. Those with $2 \mathrm{~h}$ blood glucose levels in the range $6.7-11.1 \mathrm{mmol} / 1(120-199 \mathrm{mg} / \mathrm{dl})$ inclusive (measured by the ferricyanide reduction method on an autoanalyser) were designated as borderline diabetics and were asked to participate in a prospective study, including a therapeutic trial. This paper reports the results after 10 years of observation in respect of changes in glucose tolerance and worsening to diabetes.

\section{Population, Methods, Criteria}

Two hundred and twenty-nine subjects were designated as 'borderline diabetic' after the initial Survey. Of these, one failed to attend the first follow-up clinic and seven who attended and were allocated to treatment, failed to start therapy. As treatment is one of the baseline variables considered in this analysis, these eight persons have been excluded. A further 20 borderline diabetics were derived from the Bedford Glaucoma Survey (1963-1964), which included the same modified glucose tolerance test, using identical criteria. Two hundred and forty-one subjects thus comprise the material of this report.

The following data were recorded before random allocation to treatment groups: age, height, weight, blood pressure (measured with the London School of Hygiene sphygmomanometer) triceps and subscapular skinfold thickness (with Harpenden callipers), smoking history, family history of diabetes and arterial disease, vibration perception threshold (measured with a biothesiometer on the index finger and great toe) [2], urinary albumin excretion rate (measured by radioimmunoassay in an aliquot of urine collected over $2 \mathrm{~h}$ following an oral glucose load) [3]. Therapy was allocated by a pre-arranged unstratified random assignment scheme and the four groups arose from a $2 \times 2$ design: tolbutamide $0.5 \mathrm{~g}$ twice daily or an identical placebo tablet; and dietary teaching to restrict carbohydrate intake to $120 \mathrm{~g}$ /day or brief advice simply to restrict use of table sugar. On the first visit following commencement of therapy, but 10 days after stopping tablets, an electrocardiogram was recorded and plasma insulin measured $2 \mathrm{~h}$ after a $50 \mathrm{~g}$ oral glucose load taken after a $10 \mathrm{~h}$ fast.

For the first 5 years of the study visits to the follow-up clinic in Bedford were made at approximately 6-monthly intervals. Seven further visits were made during the second 5 years. Where participants were unable to attend the clinic, visits were made by the investigators to their homes or residence, where the standardised examination was performed. Additional information was obtained in case of illness or death from general practitioners and hospitals. Postal and, where possible, physical contact was maintained with emigrants from Bedford. For all those who died during the followup period copies of death certificates were obtained. 
During follow-up, in addition to general health enquiry, subjects were regularly questioned in a standardised way for symptoms suggesting angina pectoris, myocardial infarction, intermittent claudication, stroke and the cardinal symptoms of diabetes. Baseline measurements and examinations were repeated at predetermined intervals. Capillary blood glucose was measured at every contact, in most cases $2 \mathrm{~h}$ after an oral 50 -g glucose load (as in the initial Survey), though fasting and random samples were obtained on certain occasions. At the 10-year visit (number 17) a full, $2 \mathrm{~h}$ standard oral glucose tolerance test was performed in the morning after an overnight fast. The load was $50 \mathrm{~g}$ liquid glucose (as Lucozade) and capillary blood was sampled.

During the 10-year follow-up 36 subjects fulfilled the pre-set criteria for 'worsening to diabetes'. A borderline diabetic was judged to have worsened to diabetes if, in follow-up visits, two consecutive or three non-consecutive 2 -h post-load blood glucose readings were above $11.1 \mathrm{mmol} / 1(200 \mathrm{mg} / \mathrm{dl})$. There were two exceptions to these rules. First if a subject had only one reading above $11.1 \mathrm{mmol} / 1(200 \mathrm{mg} / \mathrm{dl})$ plus clinical signs and symptoms supporting the diagnosis then that subject was recorded as worsening to diabetes (three cases). Secondly, worsening to diabetes was recorded if the $2 \mathrm{~h}$ reading at the 10 year standard glucose tolerance test (when the subject was under supervision for the whole test period) was over $11.1 \mathrm{mmol} / 1(200 \mathrm{mg} / \mathrm{dl})$ even though the other glucose requirements were not met. A total of nine subjects worsened to diabetes at the last visit and in five subjects this was the only occasion on which a $2 \mathrm{~h}$ blood glucose reading exceeded $11.1 \mathrm{mmol} / \mathrm{l}$ $(200 \mathrm{mg} / \mathrm{dl})$.

A further breakdown of the group not worsening to diabetes will be used in the following analyses. Minor 'reverters' (to normoglycaemia) are defined as those subjects (with at least six readings) in whom at least two consecutive or three non-consecutive $2 \mathrm{~h}$ blood glucose values were less than $6.7 \mathrm{mmol} / 1(120 \mathrm{mg} / \mathrm{dl})$. Major reverters are those with no more than two such blood glucose values at any time exceeding $6.7 \mathrm{mmol} / \mathrm{l}$. There were 74 minor reverters and 54 major reverters among those not worsening to diabetes. In 22 cases there were not enough data to make this classification. All other subjects are classified as persisting borderline diabetics.

\section{Results}

The effects of treatment (tolbutamide and/or diet) on glucose tolerance were not significant or important and are not described in detail here. We have used treatment allocation as independent variables in multiple logistic analyses. These analyses will detect any independent treatment effect and will allow for differences between treatment groups in baseline variables. Some differences were evident despite random allocation.

\section{Baseline Characteristics}

In Table 1 comparisons between those worsening and not worsening to díabetes are made. Mean baseline (survey) blood glucose concentration was significantly higher in those worsening to diabetes for the whole 10 years of follow-up as well as for the two 5-year periods separately. Body mass index $(\mathrm{BMI}=$ weight in $\mathrm{kg} \div$ height $^{2}$ in metres) was significantly greater in those worsening to diabetes, but only in the second 5year period. Allocation to either tolbutamide treatment or dietary advice groups had no significant effect on metabolic outcome. More men worsened to diabetes in the second 5-year period, but this sex difference was not significant $(p>0.05)$. There were no significant differences in mean age. Insulin concentration and albumin excretion rates were expressed as $\log$ values in the significance tests performed, for the distribution of these variables was approximately lognormal. Neither showed any significant differences.

If we define a subject as obese if BMI is $>25$ for men and $>27$ for women (these are the approximate 50 th centiles for men and women respectively), then 13 of the 14 subjects worsening to diabetes in years 6-10 are obese (Table 2). The serial BMI of those who worsened to diabetes showed a fall in values coincidentally with the development of the metabolic deterioration. This phenomenon was present to varying degree in 31 of the 36 subjects who worsened to diabetes. Mean weight changes before and after worsening (taking the weight at the visit when worsening was recorded as the zero value) are presented in Figure 1. Where there was doubt about whether these weight changes could have been due to clinical intervention before the visit to our clinic cases were excluded. Obesity is a complex baseline indicator of metabolic deterioration in the succeeding 10 years. Accepting our definitions of obesity, its presence at baseline doubled the risk of later deterioration (i.e. 19.5\% versus $9.3 \%$ ) over the whole 10 -year period, but this excess was concentrated in the second 5 years $(9.8 \%$ versus $0.9 \%$ ).

Of those not worsening to diabetes, some remained virtually permanently glucose intolerant (persisting borderline diabetics $n=55$ ) whereas others rapidly recovered or were only partially or temporarily intolerant (reverters, major $n=54$ and minor $n=74$ ). Although the mean age at baseline of the group not worsening was similar to that of those destined to worsen to diabetes, they comprised a mixture of older subjects who remained borderine diabetic and younger subjects who reverted to normoglycaemia, sometimes quite rapidly (Table 3 ). Age adjustment was therefore performed for the variables shown in Table 3 by stratifying each group into three age categories (under 50, 50-69 and 70 + years). Significance tests were then performed on the age adjusted means, i.e. the average of the three age group means. For proportions, the appropriate chi-squared statistic with one degree of freedom in the appropriate $3 \times 2 \times 2$ contingency table was calculated. For continuous variables the methods described by Armitage [4] were used. The 'reverters' had significantly lower mean baseline insulin concentrations and albu- 
Table 1. Bedford study: baseline variables and follow-up status

\begin{tabular}{|c|c|c|c|c|}
\hline Baseline variables & $\begin{array}{l}\text { Worsened to diabetes in } \\
\text { first } 5 \text { years }(n=22)\end{array}$ & $\begin{array}{l}\text { Worsened to diabetes in } \\
\text { second } 5 \text { years }(n=14)\end{array}$ & $\begin{array}{l}\text { Worsened to diabetes in } \\
10 \text { years }(n=36)\end{array}$ & $\begin{array}{l}\text { Not worsened to diabetes } \\
(n=205)\end{array}$ \\
\hline Age (years) & $57.3 \pm 2.4$ & $54.7 \pm 3.0$ & $56.3 \pm 1.9$ & $56.9 \pm 1.0$ \\
\hline Blood glucose (mmol/1) & $9.3 \pm 0.3^{c}$ & $8.8 \pm 0.4^{\mathrm{a}}$ & $9.1 \pm 0.1^{\mathrm{c}}$ & $7.9 \pm 0.1$ \\
\hline Body mass index $\left(\mathrm{kg} / \mathrm{m}^{2}\right)$ & $26.6 \pm 1.0$ & $29.2 \pm 1.0^{\mathrm{b}}$ & $27.6 \pm 0.8$ & $26.3 \pm 0.3$ \\
\hline $\begin{array}{l}\text { Systolic blood pressure } \\
(\mathrm{mmHg})\end{array}$ & $162.2 \pm 5.8$ & $174.2 \pm 8.2$ & $167.0 \pm 4.8$ & $164.2 \pm 2.4$ \\
\hline $\begin{array}{l}\text { Insulin (at second visit) } \\
\mathrm{mU} / 1\end{array}$ & $23.7 \pm 3.2$ & $25.5 \pm 3.7$ & $24.4 \pm 7.4$ & $22.0 \pm 1.6$ \\
\hline Triceps skinfold (mm) & $13.6 \pm 1.5$ & $19.1 \pm 3.8$ & $15.8 \pm 1.8$ & $14.9 \pm 0.7$ \\
\hline $\begin{array}{l}\text { Albumin excretion } \\
(\mathrm{mg} / 2 \mathrm{~h})\end{array}$ & $1.2 \pm 0.6$ & $1.7 \pm 2.1$ & $1.4 \pm 0.6$ & $1.4 \pm 0.4$ \\
\hline$\%$ smoking cigarettes & 27 & 23 & 26 & 30 \\
\hline$\%$ tolbutamide & 55 & 43 & 50 & 50 \\
\hline$\%$ diet & 45 & 43 & 44 & 50 \\
\hline$\%$ female & 50 & 36 & 44 & 48 \\
\hline $\begin{array}{l}\text { Family history of diabetes } \\
\text { (first degree relatives) ( } \%)\end{array}$ & 23 & 14 & 19 & 10 \\
\hline $\begin{array}{l}\text { Family history of diabetes } \\
\text { (non-first degree relatives) } \\
(\%)\end{array}$ & 14 & 7 & 11 & 11 \\
\hline
\end{tabular}

Results expressed as mean \pm SEM

${ }^{\mathrm{a}} p<0.05,{ }^{\mathrm{b}} p<0.01,{ }^{\mathrm{c}} p<0.001$ : comparisons made with not worsened group using Student's unpaired ' $\mathrm{t}$ ' test. Insulin and albumin excretion $\log$ values used for testing

Table2. Bedford study: follow-up status by baseline age and obesity ${ }^{a}$

\begin{tabular}{|c|c|c|c|c|c|c|}
\hline & \multicolumn{2}{|c|}{ Worsened to diabetes } & \multirow{3}{*}{$\begin{array}{l}\text { Steady impaired glucose } \\
\text { tolerance }\end{array}$} & \multirow{2}{*}{\multicolumn{2}{|c|}{$\begin{array}{l}\text { Reverting towards } \\
\text { normoglycaemia }\end{array}$}} & \multirow[t]{3}{*}{ Uncategorised } \\
\hline & \multirow{2}{*}{$\begin{array}{l}\text { First } \\
5 \text { years }\end{array}$} & \multirow{2}{*}{$\begin{array}{l}\text { Second } \\
5 \text { years }\end{array}$} & & & & \\
\hline & & & & Minor & Major & \\
\hline \multicolumn{7}{|c|}{ Younger ( $<50$ years) } \\
\hline Non-obese & $4(10)$ & $0(-)$ & $3(8)$ & $13(33)$ & $14(36)$ & $5(13)$ \\
\hline Obese & $1(3)$ & $5(14)$ & $0(-)$ & $12(34)$ & $15(43)$ & $2(6)$ \\
\hline \multicolumn{7}{|c|}{ Older $(>50$ years $)$} \\
\hline Non-obese & $5(7)$ & $1(1)$ & $30(43)$ & $17(25)$ & $8(12)$ & $8(12)$ \\
\hline Obese & $12(12)$ & $8(8)$ & $22(22)$ & $32(33)$ & $17(17)$ & $7(7)$ \\
\hline
\end{tabular}

Number in each category with percentage in parentheses

${ }^{a}$ Obesity defined as body mass index $>25$ for men and $>27$ for women

min excretion rates, and significantly higher body mass index and triceps skinfold thickness.

The persisting borderline diabetics form an interesting sub-group. Their initial blood glucose concentrations were intermediate between those worsening to diabetes and the 'reverters'. Their mean age was considerably and significantly higher than the other groups, they had higher plasma insulin concentrations and albumin excretion rates and were much less obese, all these differences being statistically significant (Table 3).

\section{Baseline Characteristics - Multiple Logistic Analysis}

Since baseline obesity seems to have greater impact in the second 5 years, analysis was performed separately for the two 5-year periods. Since BMI and triceps skinfold thickness are highly correlated, only BMI was included as a variable in the logistic model. The multiple logistic model was fitted by a modification of the iterative Newton-Raphson procedure method of Walker and Duncan [5] using coefficients calculated from the linear discriminant function as starting values. This method calculates the maximum likelihood solution and makes no assumptions about distribution of variables. Table 4 shows the multiple logistic model for those worsening to diabetes in the first 5 years, worsening to diabetes in the second 5-year period (excluding those worsening in the first 5 years) and also for the whole period of follow-up. Table 5 shows the model for those reverting to normogly- 
Table 3. Bedford study: baseline variables and follow-up status

\begin{tabular}{|c|c|c|c|c|}
\hline \multirow[t]{2}{*}{ Baseline variables } & \multirow{2}{*}{$\begin{array}{l}\text { Persistent impaired } \\
\text { glucose tolerance } \\
(n=55)\end{array}$} & \multicolumn{2}{|c|}{ Reversion to normal } & \multirow{2}{*}{$\begin{array}{l}\text { Significance } \\
\text { level - all } \\
\text { reverters }\end{array}$} \\
\hline & & $\begin{array}{l}\text { Minor } \\
(n=74)\end{array}$ & $\begin{array}{l}\text { Major } \\
(n=54)\end{array}$ & \\
\hline Age (years) & $67.7 \pm .1 .5$ & $54.5 \pm 1.5^{\mathrm{c}}$ & $48.7 \pm 1.8^{\mathrm{c}}$ & $p<0.001$ \\
\hline Blood glucose $(\mathrm{mmol} / \mathrm{l})$ & $8.1 \pm 0.2$ & $7.9 \pm 0.1$ & $7.6 \pm 0.2^{\mathrm{a}}$ & NS \\
\hline Body mass index $\left(\mathrm{kg} / \mathrm{m}^{2}\right)$ & $24.9 \pm 0.6$ & $27.0 \pm 0.5^{\mathrm{a}}$ & $27.0 \pm 0.6$ & $p<0.01$ \\
\hline Systolic blood pressure (mmHg) & $164.9 \pm 4.2$ & $167.9 \pm 3.6$ & $164.5 \pm 6.3$ & NS \\
\hline Insulin (at second visit) (mU/l) & $29.3 \pm 3.9$ & $19.8 \pm 2.3$ & $15.1 \pm 3.1$ & $p<0.05$ \\
\hline Triceps skinfold (mm) & $13.6 \pm 1.2$ & $17.6 \pm 1.3^{\mathrm{a}}$ & $15.7 \pm 1.2$ & $p<0.05$ \\
\hline Albumin excretion (mg/2h) & $2.4 \pm 0.8$ & $0.8 \pm 0.2$ & $0.6 \pm 0.1$ & $p<0.05$ \\
\hline$\%$ smoking cigarettes & 35 & 32 & 29 & NS \\
\hline$\%$ tolbutamide & 56 & 51 & 41 & NS \\
\hline$\%$ diet & 47 & 49 & 54 & NS \\
\hline$\%$ female & 49 & 50 & 52 & NS \\
\hline Family history of diabetes (first degree relatives) (\%) & 2 & $12^{\mathrm{a}}$ & $13^{a}$ & $p<0.05$ \\
\hline Family history of diabetes (non first degree relatives) (\%) & 7 & 12 & 13 & NS \\
\hline
\end{tabular}

Major reverter: not more than two non-consecutive 2-h blood glucose values $>6.7 \mathrm{mmol} / 1$

Minor reverter: at least three or two consecutive 2-h blood glucose values $<6.7 \mathrm{mmol} / 1$ (also not worsened to diabetes or major reverter)

Results expressed as mean \pm SEM

${ }^{\mathrm{a}} p<0.05,{ }^{\mathrm{b}} p<0.01,{ }^{c} p<0.001$ : comparison made with persistent impaired glucose tolerance group using Student's unpaired 't' test. Insulin and albumin excretion logged before testing. All continuous variables (except age) are age adjusted

(NS = not significant)

Table 4. Multiple logistic model relating worsening to diabetes and baseline variables. Calculations made separately for first 5 years, $6-10$ years, and the whole follow-up period

\begin{tabular}{|c|c|c|c|c|c|c|}
\hline \multirow[t]{2}{*}{ Independent variable } & \multicolumn{2}{|l|}{$0-5$ years } & \multicolumn{2}{|l|}{$6-10$ years $^{d}$} & \multicolumn{2}{|l|}{$0-10$ years } \\
\hline & coefficient & $t$ & coefficient & $t$ & coefficient & $t$ \\
\hline Age (years) & -0.007 & -0.32 & -0.045 & -1.53 & -0.019 & -1.06 \\
\hline Blood glucose $(\mathrm{mmol} / \mathrm{l})$ & 0.04 & $3.05^{\mathrm{b}}$ & 0.036 & $2.14^{\mathrm{a}}$ & 0.038 & $3.65^{\mathrm{c}}$ \\
\hline Body mass index $\left(\mathrm{kg} / \mathrm{m}^{2}\right)$ & -0.121 & -1.64 & 0.187 & $2.09^{\mathrm{a}}$ & 0.019 & 0.36 \\
\hline Systolic blood pressure $(\mathrm{mmHg})$ & 0.001 & 0.13 & 0.019 & 1.51 & 0.009 & 1.17 \\
\hline Insulin $(\log )(\mathrm{mU} / \mathrm{l})$ & 0.136 & 0.46 & 0.471 & 1.04 & 0.234 & 0.92 \\
\hline Albumin excretion $(\log )(\mathrm{mg} / 2 \mathrm{~h})$ & -0.049 & -0.31 & -0.073 & -0.42 & 0.003 & 0.02 \\
\hline Smoking cigarettes & -0.211 & -0.31 & 0.471 & 0.65 & 0.202 & 0.40 \\
\hline Tolbutamide & -0.086 & -0.14 & -0.392 & -0.54 & -0.038 & -0.08 \\
\hline Diet & -0.783 & -1.29 & -0.12 & -0.17 & -0.496 & -1.08 \\
\hline Sex (female) & 0.318 & 0.51 & -1.321 & -1.60 & -0.324 & -0.66 \\
\hline
\end{tabular}

a $p<0.05,{ }^{\mathrm{b}} p<0.01,{ }^{\mathrm{c}} p<0.001,{ }^{\mathrm{d}}$ Subjects worsening to diabetes in years $0-5$ excluded

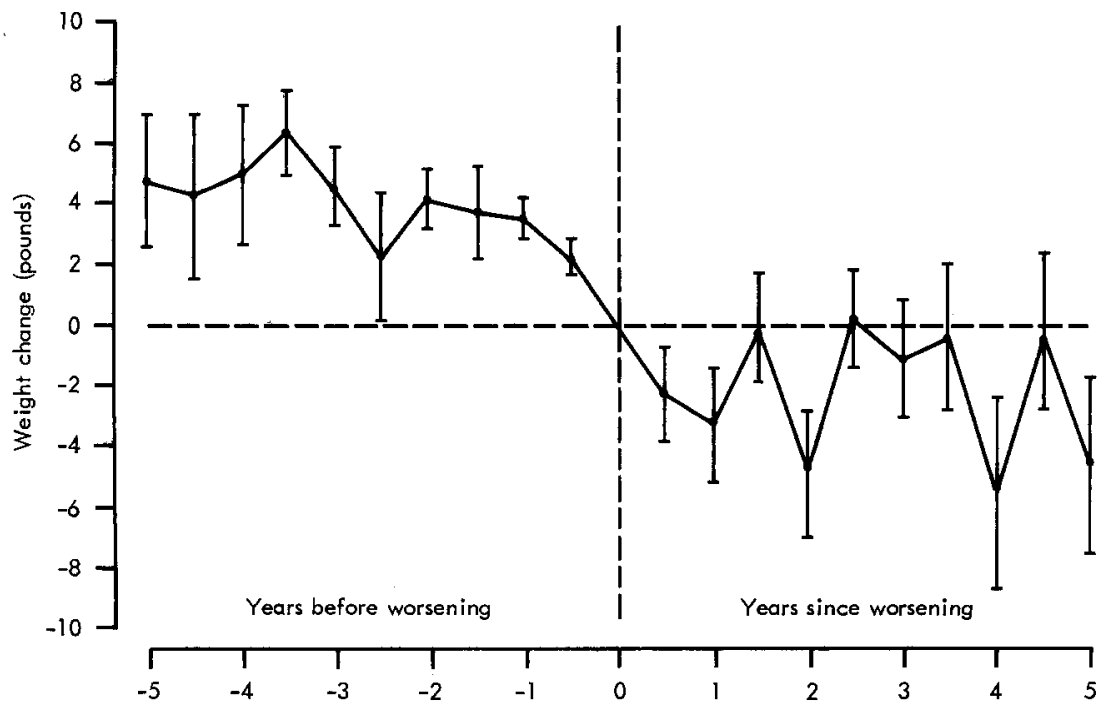

Fig. 1. Changes in weight in subjects worsening to diabetes. Zero point is the clinic visit at which worsening to diabetes was recorded. Differences from this zero value are indicated as mean \pm SEM 
caemia. Negative coefficients indicate inverse relationships.

The patterns found in the univariate analysis are consistently reflected by the multivariate analysis. Insulin concentration fails to contribute significantly to outcome in any of these multivariate analyses, although this might be expected in view of its complex relationship with blood glucose concentration. A relatively strong independent effect is necessary before significance is reached for individual variables in a sample of this size.

Only baseline blood glucose concentration, BMI and age at recruitment reach conventional levels of statistical significance in these multivariate analyses, with blood glucose following the pattern found in the univariate analysis. When all the other variables are taken into account obesity still predicts, paradoxically, both worsening to diabetes in the long term and reversion to normal. That obesity does not predict worsening in the first 5 years may be related to the loss in weight outlined in Figure 1.

\section{Discussion}

There have been several prospective studies of subjects with impaired glucose tolerance, more fully discussed by Jarrett et al. [6]. In general the major predictive index of subsequent worsening to diabetes, however defined, has been the initial identifying degree of hyperglycaemia. In two American studies [7, 8] the degree of obesity also appeared to have some predictive effect, though it is not clear from the analyses whether this was independent of other variables and how long after ascertainment it operated. In the Whitehall Study [6] we observed no independent, predictive effect of degree of obesity on worsening to diabetes during the first 5 years of observation. However, the longer period of follow-up at Bedford appeared to reveal a 'delayed diabetogenic effect' of obesity, becoming evident only in the second 5 years of the observation period. Adiposity had a complex relationship with glucose metabolism, for those whose glucose tolerance improved were also on average more obese than those who remained glucose intolerant throughout the 10 years of observation. A fall in weight fairly consistently heralded or accompanied the metabolic deterioration which we had arbitrarily pre-selected as indicating worsening to diabetes. The mechanism of this weight change is unknown. It may, in part, have been due to increased energy losses in the form of glycosuria, but urine glucose was not routinely measured. Diminished food consumption or alterations in the energy costs of altered metabolic pathways may have contributed to this phenomenon. To ascribe
Table5. Multiple logistic model relating reversion to normoglycaemia (major and minor) and baseline variables

\begin{tabular}{lcc}
\hline Variable & $\beta$ coefficient & $t$ \\
\hline Age (years) & -0.063 & $-3.98^{\mathrm{c}}$ \\
Blood glucose $(\mathrm{mmol} / \mathrm{l})$ & -0.035 & $-3.88^{\mathrm{c}}$ \\
Body mass index $\left(\mathrm{kg} / \mathrm{m}^{2}\right)$ & 0.111 & $2.51^{\mathrm{b}}$ \\
Systolic blood $\mathrm{pressure}(\mathrm{mmHg})$ & -0.008 & -1.22 \\
Insulin $(\mathrm{log})(\mathrm{mU} / \mathrm{l})$ & -0.351 & -1.77 \\
Albumin excretion $(\mathrm{log})(\mathrm{mg} / 2 \mathrm{~h})$ & -0.226 & $-2.13^{\mathrm{a}}$ \\
Smoking cigarettes & -0.311 & -0.77 \\
Tolbutamide & 0.042 & 0.11 \\
Diet & -0.333 & +0.91 \\
Sex (female) & 0.692 & 1.74 \\
\hline
\end{tabular}

${ }^{\mathrm{a}} p<0.05,{ }^{\mathrm{b}} p<0.01,{ }^{\mathrm{c}} p<0.001$

these changes to 'metabolic decompensation' of course gives no indication of the metabolic mechanisms involved.

There are many factors which can result in the final resultant of 'impaired glucose tolerance' and each is likely to show its own natural evolution, in some cases towards worsening, in others towards normalisation. In addition to such factors as the presence of genetic susceptibility to diabetes and the taking of 'diabetogenic' drugs such as corticosteroids, oral contraceptives and thiazides, there are the effects of obesity per se (and of weight change), of emotional factors and their neuro endocrine-metabolic consequences, of insulin resistance and unknown contributions to the outcome in respect of glucose tolerance. Even the influence of obesity may be dependent upon the age of the subject and the length of time it has been present. Clearly, the group that we have observed - people with borderline diabetes or 'impaired glucose tolerance' - is heterogeneous in its composition. The behaviour of individuals identified at a given point in time is likely to vary, depending upon the factors which provoked the impaired tolerance detected. Nevertheless, there may also be a common set of consequences which follow (as for example with modest degrees of elevation of arterial pressure) and further analytical study of this group is required to distinguish between the effects of impaired glucose tolerance per se and those of the factors which provoked it. One thing, however, is clear; that is that the finding of impaired glucose tolerance is unlikely to indicate an early point in an inexorably progressive metabolic deterioration. In most it is emphatically not to be equated with 'early' diabetes, though in a few it may be.

Acknowledgements. We are grateful to the participants and to the many people in Bedford and London who have helped with the study. Generous financial assistance has been provided by the Department of Health and Social Security and the British Diabetic Association. 


\section{References}

1. Sharp CL, Butterfield WJH, Keen H (1964) Diabetes survey in Bedford, 1962. Proc R Soc Med 57: 193-204

2. Jarrett RJ, Keen H, Boyns DR, Chlouverakis C, Fuller J (1969) The concomitants of raised blood sugar: studies in newly detected hyperglycaemics, 1. A comparative assessment of neurological functions in blood sugar groups. Guy's Hosp Rep 118: 237-246

3. Keen H, Chlouverakis C, Fuller J, Jarrett RJ (1969) The concomitants of raised blood sugar: studies in newly detected hyperglycaemics, 2. Urinary albumin excretion, blood pressure and their relation to blood sugar levels. Guy's Hosp Rep 118:247-254

4. Armitage P (1971) Statistical methods in medical research. Blackwell, Oxford, pp 263-268

5. Walker SH, Duncan DB (1967) Estimation of the probability of an event as a function of several independent variables. Biometrika 54: 167-179
6. Jarrett RJ, Keen H, Fuller JH, McCartney M (1979) Worsening to diabetes in men with impaired glucose tolerance ("borderline diabetes"). Diabetologia 16:25-30

7. O'Sullivan JB, Mahan CM (1965) Blood sugar levels, glycosuria, and body weight related to development of diabetes mellitus. J Am Med Assoc 194: 117-122

8. O'Sullivan JB, Mahan CM (1968) Prospective study of 352 young patients with chemical diabetes. $\mathrm{N}$ Engl J Med 278: $1038-1041$

Received: 6 November 1980

and in revised form: 28 August 1981

Dr. R. J.Jarrett

Department of Community Medicine

Guy's Hospital Medical School

London SE1 9RT, UK 